\title{
The Reaction Kinetics of LiD with Water Vapor
}

\author{
M. Balooch, L. N. Dinh, D. F. Calef
}

April 1, 2001

U.S. Department of Energy

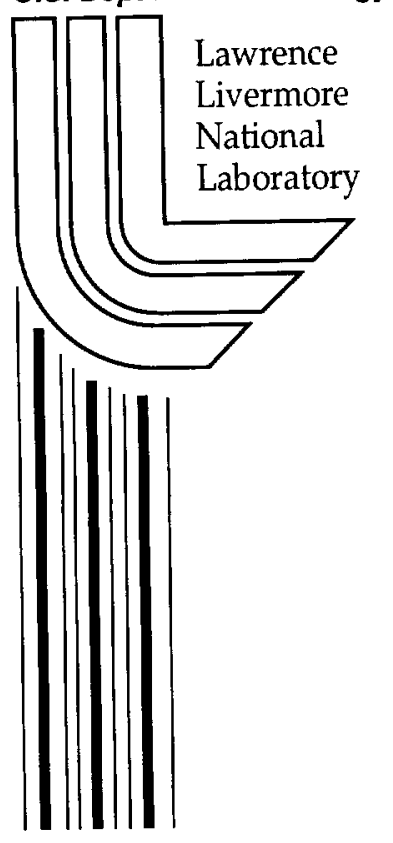




\section{DISCLAIMER}

This document was prepared as an account of work sponsored by an agency of the United States Government. Neither the United States Government nor the University of California nor any of their employees, makes any warranty, express or implied, or assumes any legal liability or responsibility for the accuracy, completeness, or usefulness of any information, apparatus, product, or process disclosed, or represents that its use would not infringe privately owned rights. Reference herein to any specific commercial product, process, or service by trade name, trademark, manufacturer, or otherwise, does not necessarily constitute or imply its endorsement, recommendation, or favoring by the United States Government or the University of California. The views and opinions of authors expressed herein do not necessarily state or reflect those of the United States Government or the University of California, and shall not be used for advertising or product endorsement purposes.

This work was performed under the auspices of the U.S. Department of Energy by the University of California, Lawrence Livermore National Laboratory under Contract No. W-7405-Eng-48.

This report has been reproduced directly from the best available copy.

Available electronically at http://www.doc.gov/bridge

Available for a processing fee to U.S. Department of Energy

And its contractors in paper from

U.S. Department of Energy

Office of Scientific and Technical Information

P.O. Box 62

Oak Ridge, TN 37831-0062

Telephone: (865) 576-8401

Facsimile: (865) 576-5728

E-mail: reports@adonis.osti.gov

Available for the sale to the public from

U.S. Department of Commerce

National Technical Information Service

5285 Port Royal Road

Springfield, VA 22161

Telephone: (800) 553-6847

Facsimile: (703) 605-6900

E-mail: orders@ntis.fedworld.gov

Online ordering: http://www.ntis.gov/ordering.htm

\section{OR}

Lawrence Livermore National Laboratory

Technical Information Department's Digital Library

http://www.llnl.gov/tid/Library.html 


\title{
The reaction kinetics of $\mathrm{LiD}$ with water vapor
}

\author{
M. Balooch, L. N. Dinh, D. F. Calef \\ Lawrence Livermore National Laboratory
}

Key word: modulated molecular beam, SEM, TGA, AFM, LiD, LiOH

\begin{abstract}
The interaction of $\mathrm{LiD}$ with water vapor in the partial pressure range of $10^{-7}$ Torr to 20 Torr has been investigated. The reaction probability of water with pure $\mathrm{LiD}$ cleaved in an ultra high vacuum environment was obtained using the modulated molecular beam technique. This probability was 0.11 and independent of $\mathrm{LiD}$ surface temperature suggesting a negligible activation energy for the reaction in agreement with quantum chemical calculations. The value gradually reduced, however, to .007 as the surface concentration of oxygen containing product ( $\mathrm{LiOH})$, which was monitored in-situ by Auger electron spectroscopy on the reaction zone, approached full coverage. As the hydroxide film grew beyond a monolayer, the phase lag of hydrogen product increased from zero to 20 degrees and the reaction probability reduced further until it approached our detection limit $\left(\sim 10^{-4}\right)$. This phase lag was attributed to a diffusion limited process in this regime. In separate experiments, the film growth has been studied in nitrogen atmosphere with $100 \%$ relative humidity using thermogravimetric analysis (TGA) and in air with $50 \%$ relative humidity utilizing scanning electron microscopy (SEM). For exposures to environment with high water concentrations and for micrometer thick films, the reaction probability reduced to $4 \times 10^{-7}$ and was independent of exposure time. The lattice diffusion through the film was no longer controlling the transport of water to the $\mathrm{LiD} / \mathrm{LiOH}$ interface. Microcracks generated in the film to release stress provided easier pathways to the interface. A modified microscope, capable of both atomic force microscopy (AFM) and nanoindentation, was employed to investigate the surface morphology of $\mathrm{LiOH}_{\mathrm{H}} \mathrm{H}_{2} \mathrm{O}$ grown on $\mathrm{LiOH}$ at high water vapor partial pressures and the kinetics of this growth.
\end{abstract}

\section{Introduction}

Low atomic number elements such as hydrogen, lithium and beryllium are essential parts of materials for neutron shielding applications. In ground-base reactors water or hydrogen-containing materials are used since the weight of shielding materials is relatively unimportant. However, for applications that are weight sensitive, such as mobile nuclear reactor, lithium hydride is an ideal material to be used for neutron shielding. The unique properties of this material include: high hydrogen content, high melting point, low dissociation pressure and low density. ${ }^{1}$ Lithium hydride, however, has a high affinity for water. For large quantity storage, the inadvertent reaction of the material with water generates hydrogen gas and heat, the combination of which present potential hazards such as fire, explosion and even possibly ignition of the salt itself. ${ }^{2}$ 
The interaction of water with salt was investigated more than two decades ago in some details. ${ }^{3-6}$ Since then, however, the efforts to understand such a complex reaction system has been missing. The early work of Machin and Tompkins ${ }^{3}$ on single crystal LiH resulted in the finding of hydrogen production between $0 \mathrm{C}$ and $121 \mathrm{C}$. The chemical nature of the solid depended on the amount of water dosed: $\mathrm{Li}_{2} \mathrm{O}$ was formed for equivalent doses to produce a monolayer or less of the reacted product, while $\mathrm{LiOH}$ was the product for higher doses. In addition, they found that the introduced water was rapidly and almost completely removed from the gas phase by the solid hydride while the hydrogen-producing process continued for several hours. They also concluded that diffusion of absorbed water to the reaction interface was not the rate-controlling factor. Myers ${ }^{3}$ used elastic proton backscattering to study the conversion of $\mathrm{LiOH}$ layers formed on $\mathrm{LiH}$ to $\mathrm{Li}_{2} \mathrm{O}$ in the temperature of $200 \mathrm{C}-280 \mathrm{C}$. Over this temperature range, Myers observed that the interaction rate was not uniformed but varied by two orders of magnitude. The conversion was found to proceed via two reaction fronts, one advancing from the $\mathrm{LiH}-\mathrm{LiOH}$ interface, the other from the surface. From the analysis, it was concluded that reactions at the two fronts were the limiting step in the overall process and an activation energy of $31 \mathrm{kcal} / \mathrm{mole}$ for this conversion process was deduced. No follow up report exists in the literature since the careful studies of Myers ${ }^{3}$.

In the present work, the interaction of water with salt has been investigated with a varieties of techniques. The interaction of pure $\mathrm{LiH}$ with $\mathrm{H}_{2} \mathrm{O}$, up to thin $\mathrm{LiOH}$ coverage, was studied by molecular beam mass spectrometry. This technique is suitable for reaction probabilities determination greater than $10^{-4}$. For thick film (on the order of micrometers), where the reaction probability falled below this number, SEM and TGA have been employed.

\section{Experimental setup and results}

\section{Low exposure studies by modulated molecular beam mass spectrometry}

In this technique, a modulated (i.e., synchronously chopped) beam of molecules impinges on a solid surface maintained in an ultra-high vacuum environment and the consequences of the interaction are detected by an in situ mass spectrometer which views the impingement spot. The experimental program is devoted exclusively to reactions wherein the solid is either consumed by the reactant gas via formation of volatile reaction products or grown by cracking of the incident beam on the substance. The object of the experiments is to analyze the overall heterogeneous reaction in terms of elementary steps, which include adsorption (sticking) of the reactant, surface or bulk diffusion of surface intermediates, surface reaction of adsorbed species, and desorption of products. In addition to mechanistic interpretation of the reaction, the modulated molecular beam method permits quantitative determination of the rate constants of the elementary steps involved.

The power of the modulated molecular beam technique applied to gas-solid reactions is due principally to the combination of reaction probabilities and phase lag information which the experiment provides and to the exploitation of the modulated frequency as a basic variable in addition to temperature and pressure. The reaction probability is the fraction of the incident reactant molecules which adsorb on the surface and then leave as part of a product molecules. The phase lag of the product emission 
relative to the incident reactant flux is a measure of the mean lifetime of the beam species on the surface. The phase lag contains kinetic information unobtainable in conventional steady state kinetic technique, which yield only the reaction probability. In addition, the modulation technique improves the signal to noise ratio in compare to steady state detection since the background noise can be eliminated through lock-in detection process. The basic elements of the experimental set up are explained in detail previously ${ }^{4}$. In the present work, an in situ AES has been added to monitor the reaction spot on the surface of salt. The schematic of the experimental setup is shown in figure 1. The samples can be cleaved in the system to assure fresh surface exposure.

Figure 2 shows the reflected water molecules signal as a function of time as the fresh surface was exposed to $10^{-7}$ Torr equivalent water pressure from the molecular beam. The reflected signal initially rose with time then leveled off after about 60 seconds exposure. At this point the sample was moved to provide a fresh spot. This caused the reflected signal to drop to almost the same value as at the start of the previous cycle. The reaction probability can be written as:

$$
\varepsilon_{\mathrm{H}_{2}}(\mathrm{t})=1-\frac{\mathrm{S}_{\mathrm{H}_{2} \mathrm{O}}(\mathrm{t})}{\mathrm{S}_{\text {sat }}}
$$

where $\mathrm{S}_{\text {sat }}$ is the reflected $\mathrm{H}_{2} \mathrm{O}$ after leveling off. This is when the surface gets saturated with oxygen (i. e. full coverage). Assuming negligible reaction probability at saturation, the reaction probability obtained from equation (1) is estimated to be 0.12 for the fresh surface.

The reaction probability can also be estimated by monitoring hydrogen, produced as the volatile species. This reaction probability can be written as:

$$
{ }^{\varepsilon} \mathrm{H}_{2}(\mathrm{t})=\frac{\mathrm{S}_{\mathrm{H}_{2}}}{\mathrm{~S}_{\text {sat }}} \frac{{ }_{\mathrm{H}_{2} \mathrm{O}}}{{ }^{\sigma} \mathrm{H}_{2}}
$$

Where $\sigma_{\mathrm{H}_{2} \mathrm{O}}$ and $\sigma_{\mathrm{H}_{2}}$ are ionization cross sections of water and hydrogen.

Figure 3 shows the time dependence of the reaction probability through hydrogen detection along with oxygen coverage measured simultaneously by AES. The reaction probability of about 0.11 obtained for the fresh surface is within experimental error that was deduced earlier on by $\mathrm{H}_{2} \mathrm{O}$ reflected signal. The probability was reduced, however, as the oxygen containing lithium compound coverage increased. For the full coverage, the probability was about 0.007 . The reaction probability of 0.007 previously reported by Gregory and $\mathrm{Mohr}^{7}$ is, thus, suspected to be on oxygen contaminated surface. 
The hydrogen production probability as a function of salt temperature is shown in figure 4. The sample was moved between each measurement to insure fresh salt exposure to molecular beam. The probability is calculated from:

$$
{ }^{\varepsilon} \mathrm{H}_{2}(\mathrm{t})=\frac{\mathrm{S}_{\mathrm{H}_{2}}^{\mathrm{T}}}{\mathrm{S}_{\mathrm{H}_{2} \mathrm{O}}^{300}} \frac{{ }^{\sigma} \mathrm{H}_{2} \mathrm{O}}{{ }^{\sigma_{H_{2}}}}\left(\frac{\mathrm{T}}{300}\right)^{\frac{1}{2}}\left(\frac{{ }_{\mathrm{H}_{2} \mathrm{O}}}{\mathrm{M}_{\mathrm{H}_{2}}}\right)^{\frac{1}{2}}
$$

where $S_{\mathrm{H}_{2}}^{T}$ and $S_{\mathrm{H}_{2} \mathrm{O}}^{300}$ are hydrogen and water signals at temperature $\mathrm{T}$ and $300 \mathrm{~K}$, respectively. $M_{\mathrm{H}_{2} \mathrm{O}}$ and $\mathrm{M}_{\mathrm{H}_{2}}$ are molecular weight of hydrogen and water. The last two terms are required to account for the fact that the mass spectrometer is a density sensitive device. The insensitivity of the reaction probability to change with temperature suggests that the activation energy for the reaction was negligible for pure salt. An activation energy of $22 \mathrm{kcal} / \mathrm{mole}$ has been reported by McIntyre and $\mathrm{Smith}^{8}$ while Myers ${ }^{3}$ measured $31 \mathrm{kcal} / \mathrm{mole}$. We suspect these values may have been obtained from samples that have hydroxide film already developed on them. Even in an ultra-vacuum system, full surface conversion to oxygen-containing product takes less than few hours.

The hydrogen reaction probability and phase lag of desorbed hydrogen with respect to scattered water molecules are shown in figure 5, following the completion of oxygen coverage. This probability still reduced further with time while hydrogen phase lag increased to over 20 degrees. Since the interaction of water with pure LiD did not produced measurable phase lag, the increase in this phase lag is attributed to the time required for water to diffuse through the $\mathrm{LiOH}$ lattice and to react at the interface. As the thickness of the film increased, the phase lag increase along with it. This also implies that the $\mathrm{LiOH}$ film preserved its integrity, at least at the early stage of film growth. However, due to lattice parameter mismatch between $\mathrm{LiD}$ and $\mathrm{LiOH}$, cracks were eventually generated to release stress as can be seen in the following section.

\section{High pressure exposure studies by SEM, TGA and modified AFM SEM studies}

A single crystal of $\mathrm{LiD}$ was cleaved to obtain two perpendicular $\{100\}$ surfaces for SEM studied. As a result of exposure to air with $50 \%$ relative humidity, the hydroxide started to grow on salt surfaces. Due to the lattice mismatch between $\mathrm{LiD}$ and $\mathrm{LiOH}$, stress built up as the hydroxide film grew. At the yield point, the comers fractured to relieve stress. The lines developed on hydroxide as it grew are the indication of the thicknesses where fracture took place (Fig. 6). The observed growth by SEM is not the actual thickness since SEM measures the thickness with respect to the starting corner as shown in Fig. 6 . The actual distance, $\mathrm{X}$, can be deduced by density ration of LiOH to LiD. The time evolution of observable hydroxide growth at $50 \%$ humidity as monitored by SEM in situ is shown in figure 7. The actual hydroxide thickness, $\mathrm{X}$, as a function of exposure is shown in figure 8 . The thickness varied linearly with exposure for films having thickness on the order of micrometers suggesting, unlike thin hydroxide film, the growth was not longer controlled by the diffusion through the hydroxide film as observed by molecular beam experiment on thin film. The absence of a diffusion limitation does 
not necessarily imply that the lattice diffusion was rapid. The extensive microcracking observed during exposure offered a possible pathway for water migration to the $\mathrm{LiH} / \mathrm{LiOH}$ interface. The reaction probability, defined as the number of $\mathrm{LiOH}$ produced to the number of water molecules striking at the surface, is estimated to be around $5 \times 10^{-7}$. This value is six orders of magnitude lower than the reaction probability obtained by molecular beam analysis on bare LiD surfaces.

II. Thermogravimetric studies

The rate of weight gain as a function of temperature in nitrogen atmosphere saturated with water is shown in figure 9 . The LiD single crystal slab ( $1 \mathrm{~cm}^{2}$ each side) was cleaved prior to being introduced into the vacuum system that housed the microbalance. The system was evacuated with a turbo molecular pump to about $10^{-7}$ Torr prior water vapor introduction. The measured weight gain in time was about $7.5 \mathrm{mg} / \mathrm{hr}$ at room temperature. This implies an oxygen uptake of $7.6 \times 10^{16}$ atoms per second. The number of collision of $\mathrm{H}_{2} \mathrm{O}$ molecules to the face of the sample can be obtained from kinetic theory of gases :

$$
v=\frac{3.5 \times 10^{22} \mathrm{P}(\text { Torr })}{\sqrt{\mathrm{M}_{\mathrm{H}_{2} \mathrm{O}} \mathrm{T}(\mathrm{K})}} \mathrm{A}\left(\mathrm{cm}^{2}\right)
$$

For saturated water vapor, the number of collisions is about $1.7 \times 10^{22}$. Therefore the reaction probability is estimated to be $4.5 \times 10^{-7}$, in good agreement with SEM studied. The rate was independent of exposure time at constant temperature suggesting the lack of diffusion controlled process. The rate reduced, however, by almost an order of magnitude as the temperature increased to $40 \mathrm{C}$. From then on the reduction in rate became small.

To confirm the TGA result on the temperature dependence of growth, cross sectional studied by SEM were performed on two single crystal LiD slabs at two different temperatures. Fig. 10 shows the growth of hydroxide as a $\mathrm{LiD}$ single crystal slab was exposed to air with $50 \%$ relative humidity, labeled "Sample 1a", for 30 hours at $T=300$ K. This resulted in $\sim 30 \mu \mathrm{m}$ thick of reacted layer. "Sample 1a" and "Sample $1 \mathrm{~b}$ " were originally from the same LiD single crystal which was subsequently cleaved into two smaller pieces. "Sample $1 \mathrm{~b}$ " was subjected to the same moisture exposure conditions as "Sample 1a", except at a slightly elevated temperature of $\mathrm{T}=339 \mathrm{~K}$. The reacted layer from "Sample $1 \mathrm{~b}$ " was less than $2 \mu \mathrm{m}$, confirming the TGA result.

\section{AFM studies}

Phase diagram suggests that the stable product in $15 \%$ or higher humidity at room temperature is $\mathrm{LiOH} . \mathrm{H}_{2} \mathrm{O}$. At about $60 \mathrm{C}$, the phase transition to $\mathrm{LiOH}$ takes place (Fig. 11). However, at this moisture level, it appears that the formation of $\mathrm{LiOH}_{2} \mathrm{H}_{2} \mathrm{O}$ is kinetically controlled. Smaller growth rate of this phase translates to a formation of $\mathrm{LiOH}$.H2O film on the top of $\mathrm{LiOH}$. The attempt to identify this phase with SEM failed, since as the film grew, the roughness increased accordingly. An attempt was made to measure this rate as well as mechanical properties of the films by a modified AFM technique as explained below. 
The AFM used in this study was a Nanoscope III ( Digital Instruments, Santa Barbara, CA) with the standard head replaced with a Triboscope indentor system (Hysitron Inc., Minneapolis, MN) as previously described (Balooch et al, 1998). In this configuration the standard AFM head is replaced by a capacitive sensor. The sensor consists of two fixed outer electrode (drive plates) that are driven by AC signals 180 degrees out of phase relative to each other. Due to the small spacing between the two plates, the electric field changes linearly from one to the other. Therefore the electric field potential is maximum at the drive plates and zero at the center between the two plates. The center, or pickup electrode is suspended in a manner that allows it to move up and down in the region between the two drive plates. The pickup electrode assumes the electric potential of the space between the two drive plates. This results in a bipolar output signal that is equal in magnitude to the input signal at the maximum deflection, and zero at the center position. The synchronous detector converts the phase and amplitude information from the sensor output into a bipolar DC output signal. The output signal is actually a reading of the pickup electrode position. In the imaging mode, this signal is used as a feedback to the piezoceramic tube for constant force contact imaging. In the indentation mode, the feedback is cut off and a voltage ramp is applied to the lower drive plate. As a result, an electrostatic force is generated between the pickup electrode and the drive plate. The force can be described as,

$$
\mathrm{F}=\mathrm{k}_{\mathrm{e}} \mathrm{V}^{2}
$$

where $\mathrm{k}_{\mathrm{e}}$ is the electrostatic force constant and $\mathrm{V}$ is the applied voltage. The voltage ramps are formulated to produce triangular, trapezoidal or square force loading profiles of the sample. For experiments in air, the force is applied to the sample through a diamond tip glued to a tapped polymer holder attached to a pickup electrode by a small screw. In the imaging mode the minimum contact force applied to the sample is about $1 \mu \mathrm{N}$. In the indentation mode, load up to $30,000 \mu \mathrm{N}$ can be applied. A cube corner indenter with a tip radius of curvature of about $20 \mathrm{~nm}$ was used for both imaging and indentation.

The hardness, $H$, is calculated on the basis of maximum force, $F_{\max }$, divided by the projected contact area at maximum load, $a$, and the elastic modulus , E, is calculated from the contact stiffness, $S$, defined as the slope of the linear portion of the force/displacement curve during unloading near the maximum load (Doerner and Nix, 1986; Harding et al, 1995 ):

$$
\begin{aligned}
& H=\frac{F_{\text {max }}}{a} \\
& E=\sqrt{\frac{p}{a}} \frac{s}{2}
\end{aligned}
$$

Fig. 12 shows the morphology and the indentation into the $\mathrm{LiOH} . \mathrm{H}_{2} \mathrm{O}$ region grown on the $\mathrm{LiOH}$ film. The surface became rougher with large amount of porosity as time went on. The force-displacement cures for different exposure at $50 \%$ relative humidity are shown in fig. 13. The $\mathrm{LiOH} . \mathrm{H}_{2} \mathrm{O}$ film appeared to be much softer than $\mathrm{LiOH}$. As a result, a noticeable change in the slope observed as the indenter penetrated through the $\mathrm{LiOH} . \mathrm{H}_{2} \mathrm{O} / \mathrm{LiOH}$ interface. The depth at which the change of in the slope 
occurred is a measurement of the $\mathrm{LiOH} . \mathrm{H}_{2} \mathrm{O}$ film thickness. The variation of $\mathrm{LiOH} . \mathrm{H}_{2} \mathrm{O}$ film thickness with exposure is shown in fig. 14. The film grew linearly with time suggesting the lack of a diffusion-controlled process, as expected for such porous film. The rate of growth is calculated to be $0.363 \mathrm{~nm} / \mathrm{minute}$ which is a factor of 60 less than the growth of $\mathrm{LiOH}$ film at the same condition.

The mechanical properties of $\mathrm{LiD}, \mathrm{LiOH}$ and $\mathrm{LiOH} . \mathrm{H}_{2} \mathrm{O}$ are summarized in table1. The elastic modulus of $\mathrm{LiOH} . \mathrm{H}_{2} \mathrm{O}$ is an order of magnitude less than $\mathrm{LiOH}$ and its hardness is a factor of two lower.

Table 1. Elastic modulus, $\mathrm{E}$ and hardness, $\mathrm{H}$ of LiD. $\mathrm{LiOH}$ and $\mathrm{LiOH} . \mathrm{H}_{2} \mathrm{O}$

\begin{tabular}{|l|l|l|l|}
\cline { 2 - 4 } & $\mathrm{LiD}$ & $\mathrm{LiOH}$ & LiOH.H ${ }_{2} \mathrm{O}$ \\
\hline $\mathrm{E}(\mathrm{GPa})$ & $40( \pm 3)$ & $32( \pm 2)$ & $3( \pm 2)$ \\
\hline $\mathrm{H}(\mathrm{GPa})$ & $1.5( \pm 0.2)$ & $1( \pm 0.2)$ & $0.5( \pm 0.2)$ \\
\hline
\end{tabular}

\section{Quantum chemical calculations}

The thermodynamic barriers to simple bi-molecular reactions can often be calculated using standard quantum chemical methods. We have investigated the reaction of a water molecule with a lithium hydride molecule. This is clearly the simplest model reaction for the experimental study of lithium hydride solid with a water vapor.

The calculations were performed using the GAMESS (General Atomic and Molecular Electronic Structure System). GAMESS is a general purpose electronic structure code that supports a wide variety of basis sets and methods. Specifically, we used the high quality G631 basis set.

The calculations used the geometric optimization features of the code. We constructed an initial geometry for $\mathrm{H}_{2} \mathrm{O}$ and $\mathrm{LiH}$ using classical molecular mechanics (CHEM3D). This, the reactant geometry, was then optimized using GAMESS by minimizing the energy. The normal, or harmonic, modes at this minimum were found. By examining the normal modes in detail, we found modes that corresponded to motion of the oxygen atom toward the lithium atom. We then used the saddle point optimization feature to search along those modes for a saddle point. Next, starting at that saddle point, the paths of steepest descent down the two sides of the saddle were found. Paths that lead down one side to reactants and the other side to the products are possible reaction pathways and the saddle point is the transition state. In general, some procedure like this 
is required as even a very small molecular system such as this one generates a 12 dimensional potential energy surface.

This procedure was done using two levels of theory, standard Hartree-Fock (HF) and the second order Moeller-Plesset (MP2) perturbation theory. MP2 is a correction to $\mathrm{HF}$ that partially incorporates the correlation effects neglected by HF. As transition state structures have unusual bonding patterns, these corrections can be important.

The results of the calculation are shown in figure 15 . Here we have plotted the calculated energy, relative to the transition state, at 45 points along the reaction path. Point 1 is $\mathrm{LiH}+\mathrm{H} 20$ and point 45 is $\mathrm{LiOH}+\mathrm{H} 2$. At the HF level, there is a $13 \mathrm{kcal}$ activation energy, but introducing the MP2 correction reduces this to $4 \mathrm{kcals}$. That relatively small number is essentially in the noise of quantum chemical calculations, so we conclude that the barrier is extremely small. This agrees with the results of the experiment.

\section{Discussion}

The overall reaction rate consists of adsoption /desoption of water on the surface, transport through the hydroxide film to the $\mathrm{LiD} / \mathrm{LiOH}$ interface and the reaction with salts at the interface. Any of these elementary steps can control the overall reaction rate. Adsorption depends highly on chemical composition, structure and concentration of surface impurities. The transport rate through the film can also drastically change depending the condition of the film. For epitaxially grown films, the diffusion through the lattice controls the transport. For films grown on substrates with large lattice mismatch, cracks generated beyond a certain thickness to relieve stress in the film can provide easy pathways from the surface to the interface. This is certainly the case for the growth of $\mathrm{LiOH}$ on LiD substrate.

The reaction probability of water with pure salt was found to be 0.11 and independent of the salt temperature. Recently Broughton ${ }^{9}$ has applied force field and quantum mechanical computational techniques to study the reaction by bringing individual water molecules to a "slab" of lithium hydride surface. While absolute energy values have been compromised using various approximations to reduce computational time, the results confirmed that there is little or no barrier for the reaction to proceed. This is in agreement with our molecular beam results. The activation energy of $32 \mathrm{kcal} / \mathrm{mole}$ reported previously ${ }^{2}$ is likely to be on oxidized surface. The reaction probability previously reported ${ }^{5}$ of .007 appear also to be on oxidized surface. Our results from figures 2 and 3 strongly support this assumption.

As multilayers, but thin, film grows on the salt, appreciable phase lag is observed on desorbed hydrogen, suggesting that the reaction is controlled by diffusion through the film (up to some thickness). However stress builds up as the thickness of the film increases. Approaching yield stress, the film fractures to provide less resistance pathways for transporting water to the $\mathrm{LiD} / \mathrm{LiOH}$ interface.

At micron size thickness and at high concentration of water exposure (e.g. 50 to $100 \%$ relative humidity in air) the reaction probability further reduces to $4 \times 10^{-7}$. The rate of growth is linear with time, implying that diffusion is not the rate controlling step in this regime. One explanation for the reduction of the reaction probability in this regime as compared to thin films studied by molecular beam is the formation of $\mathrm{LiOH}_{\mathrm{H}} \mathrm{H}_{2} \mathrm{O}$ near the 
top surface as suggested by our AFM studies. If the sticking probability on LiOH. H2O is smaller than $\mathrm{LiOH}$, the rate limiting step could be the adsoption in this regime.

The rate of hydride growth drastically reduces as the temperature is increased by $30 \mathrm{C}$ above room temperature. With a relative humidity level of $15 \%$ or greater, thermodynamics calculations suggest a phase transition to occur between $\mathrm{LiOH} . \mathrm{H}_{2} \mathrm{O}$ and $\mathrm{LiOH}$ at around $50 \mathrm{C}$. The change in sticking probability from $\mathrm{LiOH} \cdot \mathrm{H}_{2} \mathrm{O}$ to $\mathrm{LiOH}$ and/or the increase in the desorption rate of water from the surface can account for the reduction in weight gain rate.

\section{Summary}

Many techniques were used to obtain insight on the $\mathrm{LiD}$ water reaction system. We found that he reaction probability is strongly influenced by the partial pressure of water, temperature and the state of $\mathrm{LiOH}$ and/or $\mathrm{LiOH} . \mathrm{H}_{2} \mathrm{O}$ produced.

\section{References}

1. F. H. Welch, Nuclear Eng. Design 26, 444(1974).

2. J. H. Leckey, L. E. Nulf and J. R. Kirkpatrick, Langmuir, 12, 6361(1996).

3. S. M. Myers, J. Appl. Phys. 45, 4320(1974).

4. M. Balooch and D. R. Olander, J. Chem. Phys.,.....

5. W. D. Machin and F. C. Tonpkins, Trans. Faraday Soc. 62, 2205(1966).

6. C. E. Holcombe and G. L. Powell, J. Nuclear Mat. 47, 121(1973).

7. N. W. Gregory and R. H. Mohr, J. Am. Chem. Soc.. 77, 2142 (1955).

8. J. M. McIntyre and H. M. Smith, Am. Chem. Soc. Paper abstracts for the S. E. and S. W. Regional Meeting, Dec. 2-4, 1970,p. 174.

9. D. A. Broughton, technical report No. 070/99 AWE, Aldermaston U.K. 


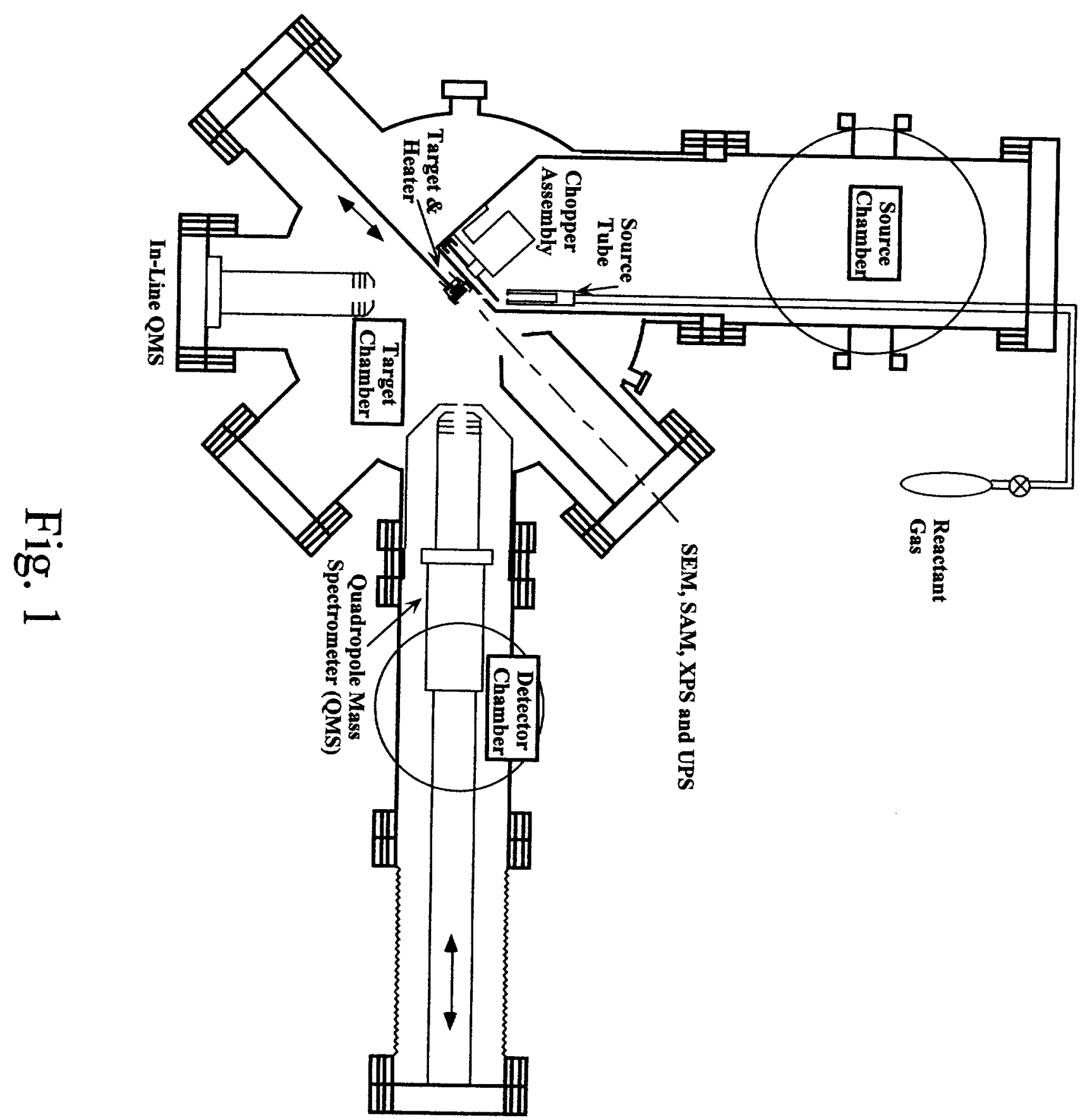


Reflected $\mathrm{H}_{2} \mathrm{O}$ signal ( $\mu \mathrm{v}$ )

$\stackrel{N}{N}$

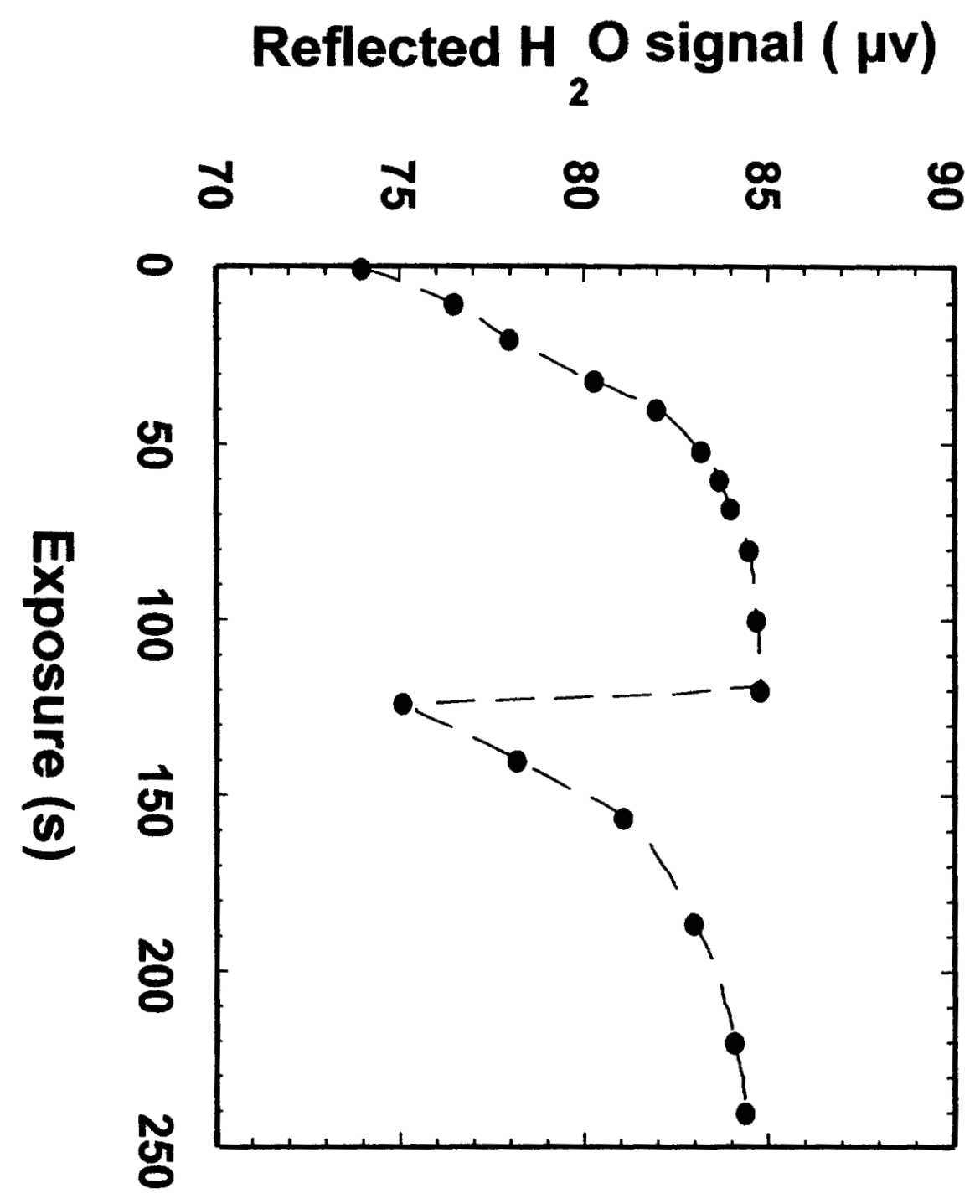


Hydrogen production probability

$\stackrel{7}{7}$

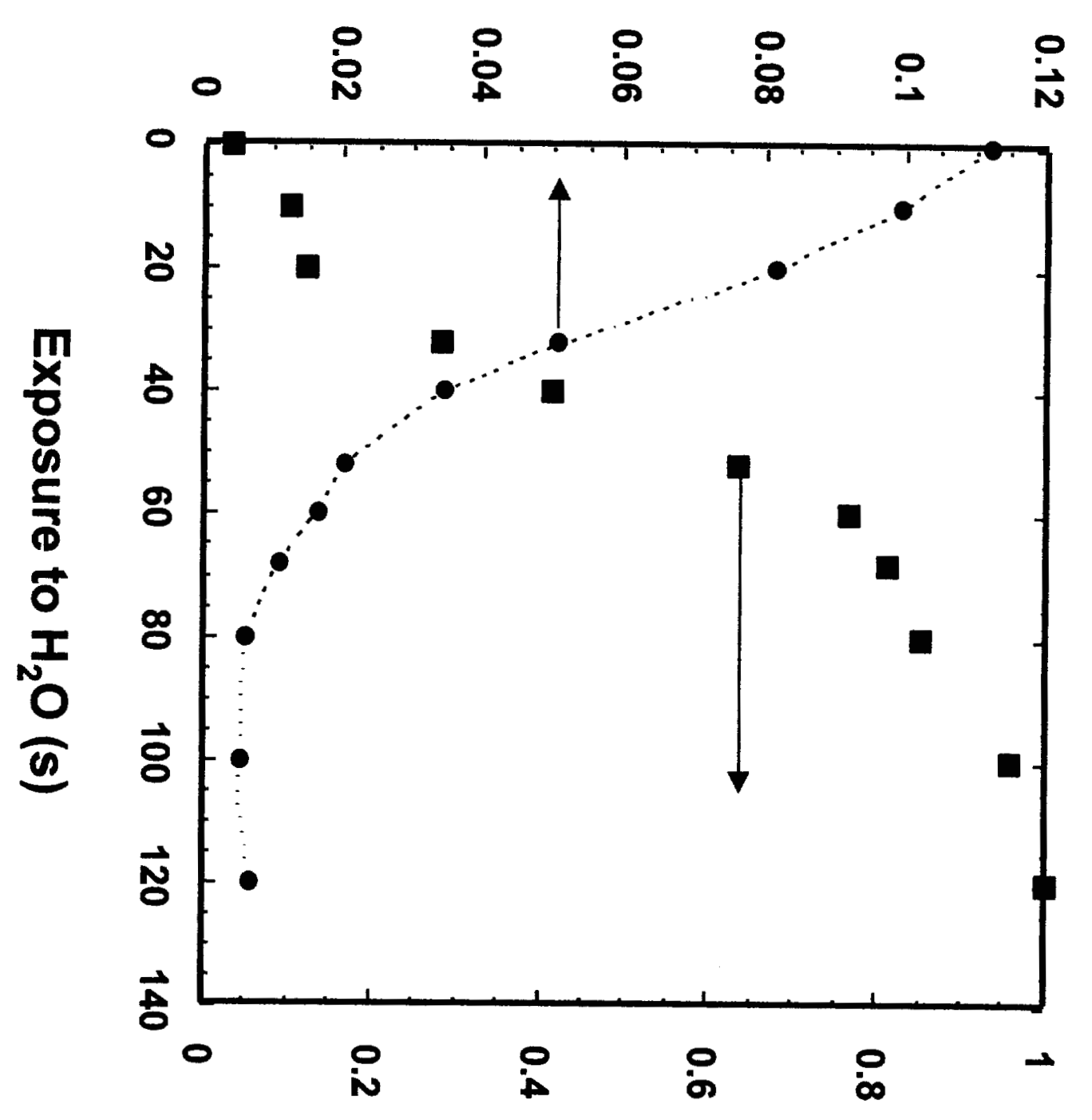

Surface oxygen coverage 
$H_{2}$ production probability

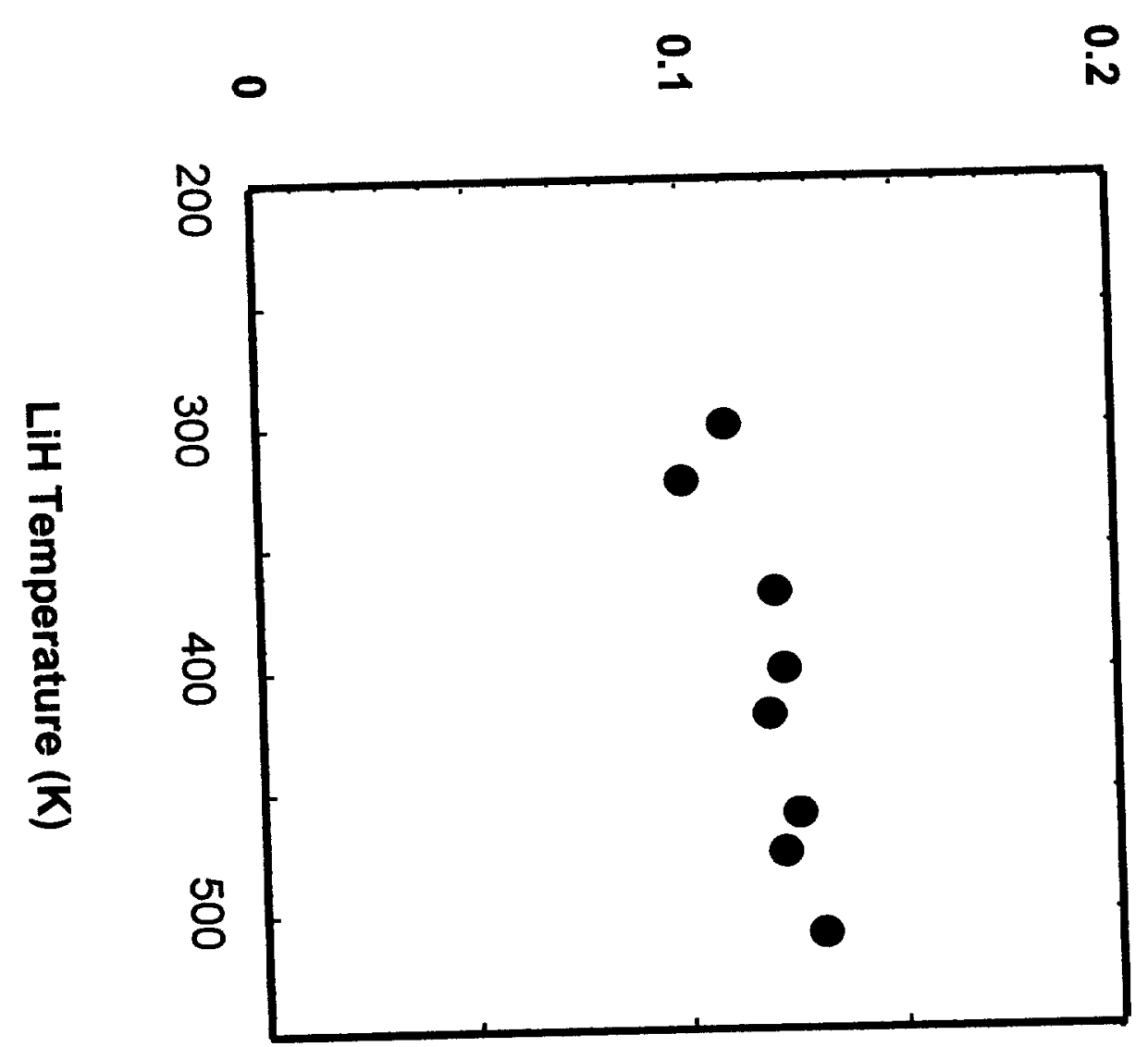


Apparent $\mathrm{H}_{2}$ Production Probability

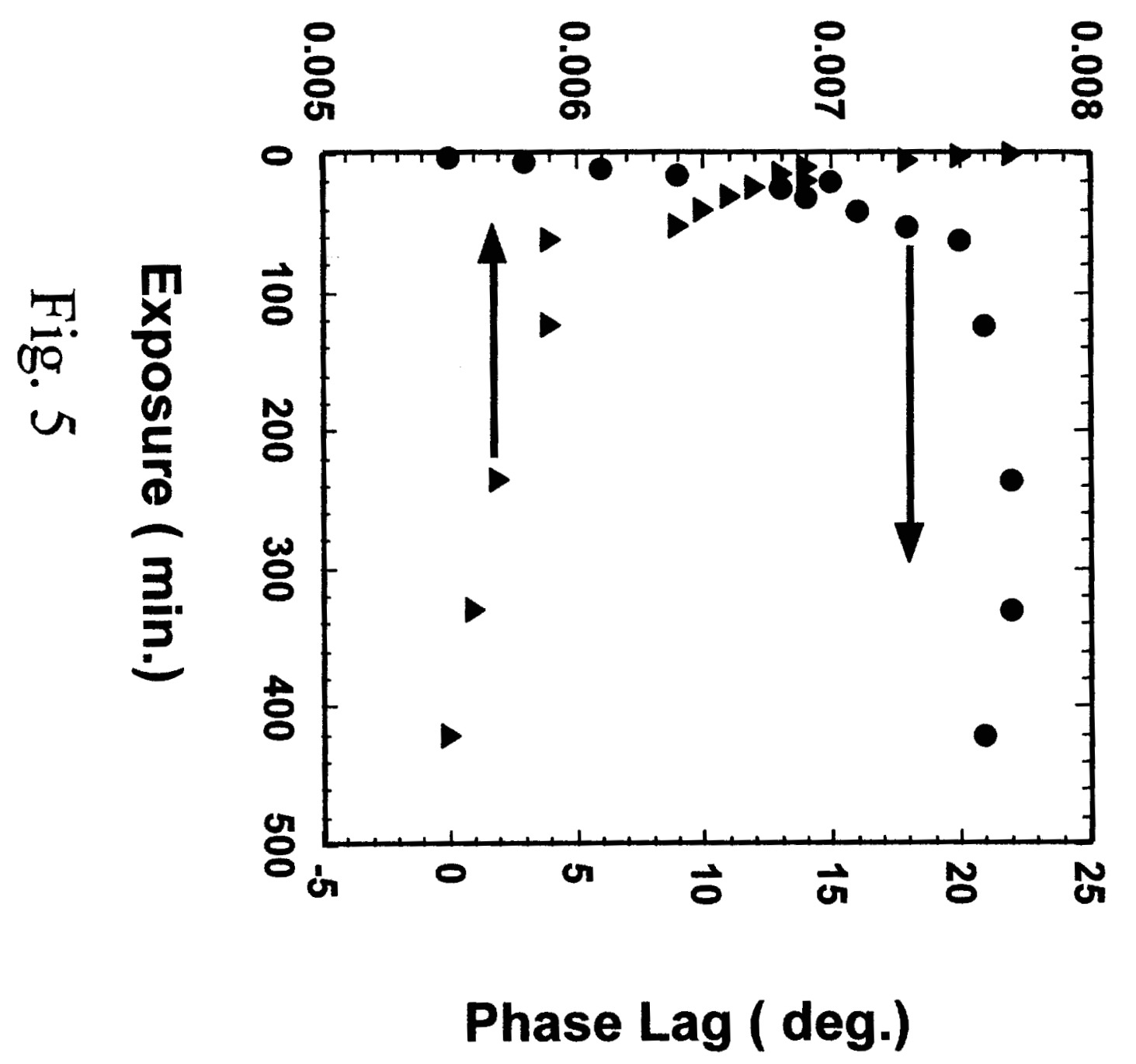




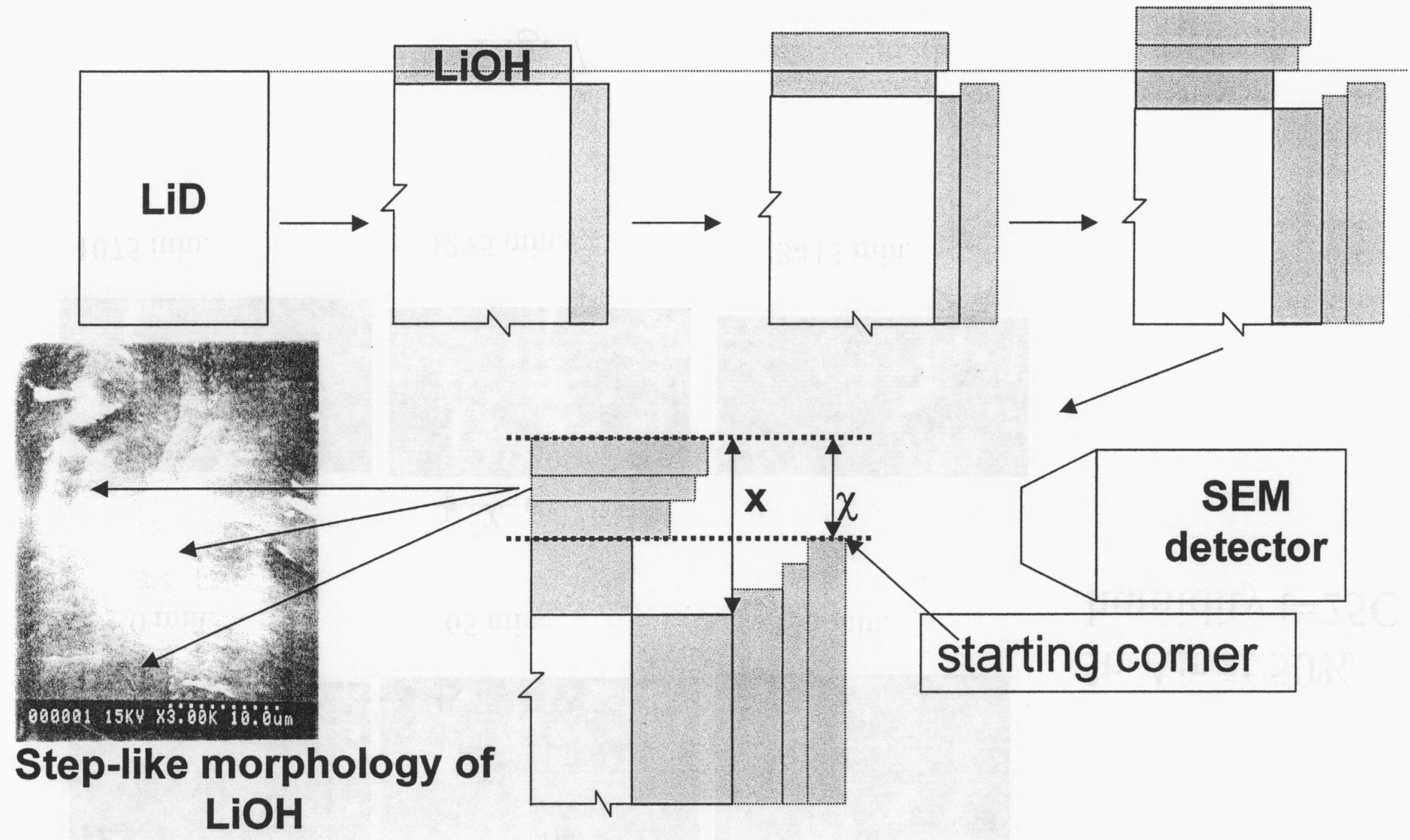

Fig. 6 


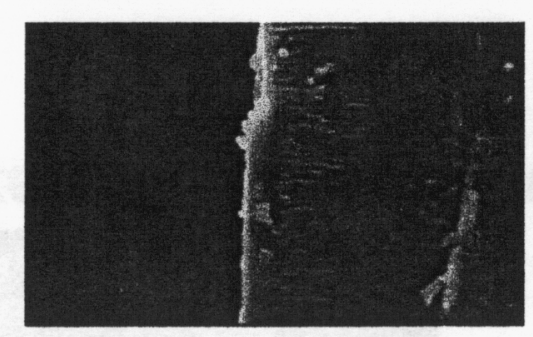

0 min.

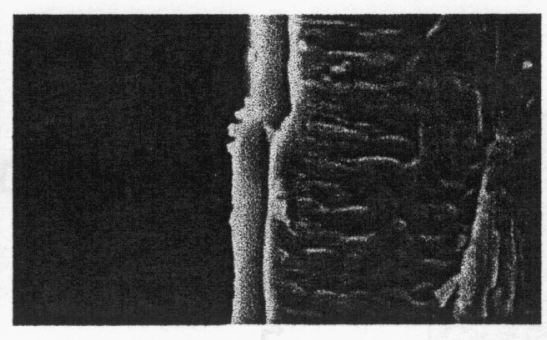

$65 \mathrm{~min}$.

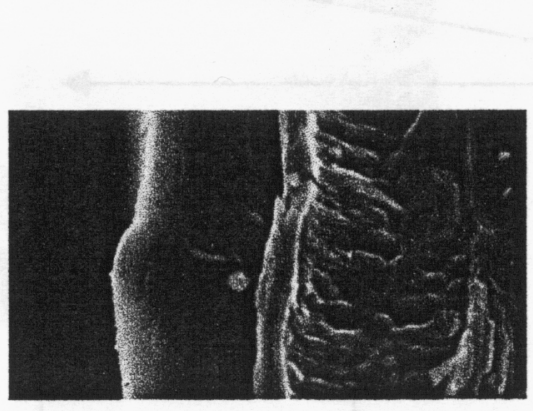

$1075 \mathrm{~min}$.

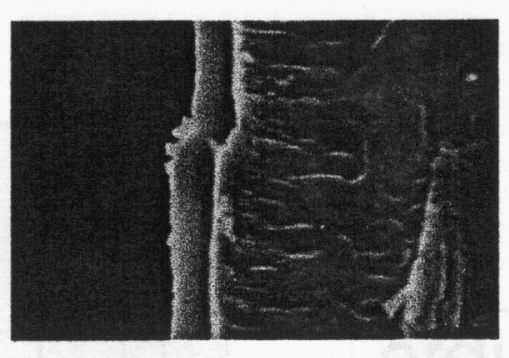

$135 \mathrm{~min}$.
In Air at 50\% humidity $\mathrm{t}=25 \mathrm{C}$

Fig. 7 


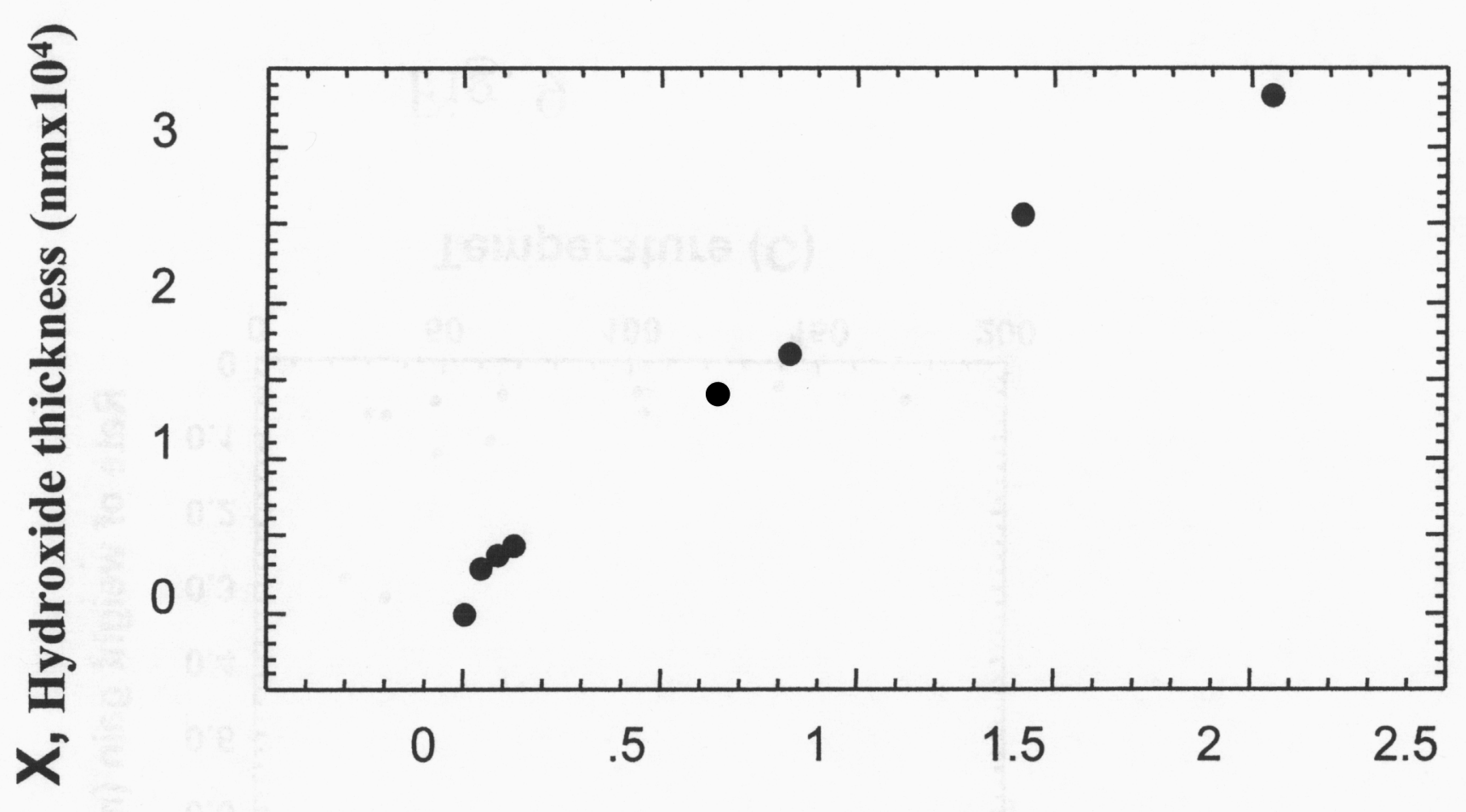

Ambient exposure time $\left(\mathrm{sx}^{10} 0^{+5}\right)$

The calculated reaction probability is $4 \times 10^{-7}$

Fig. 8 


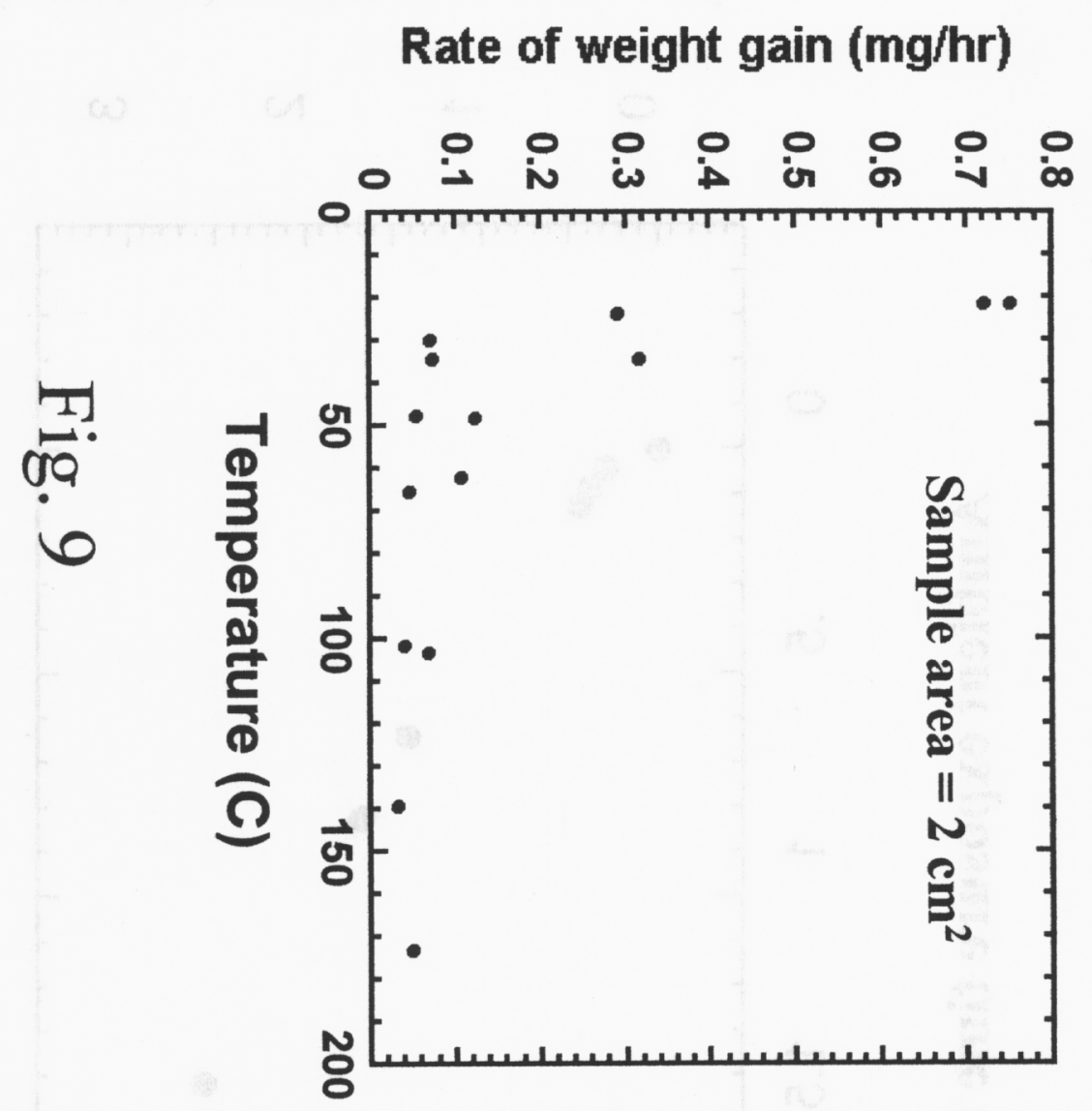




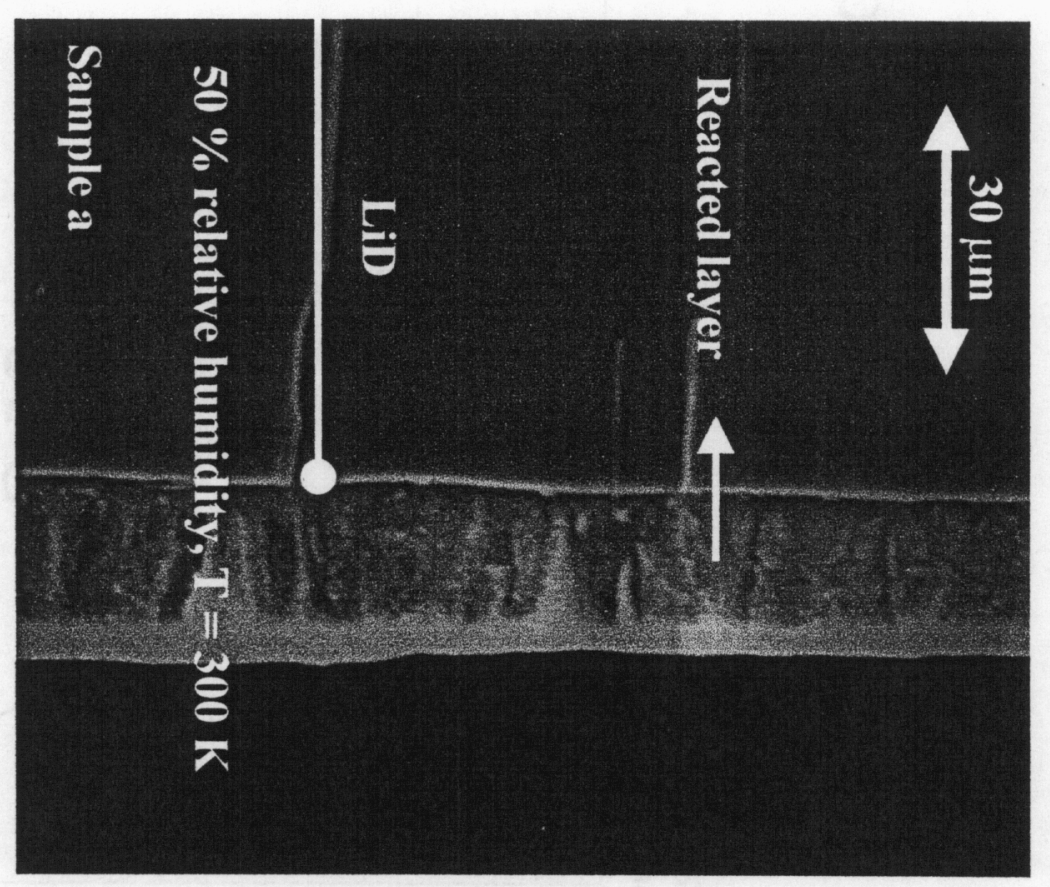

管.

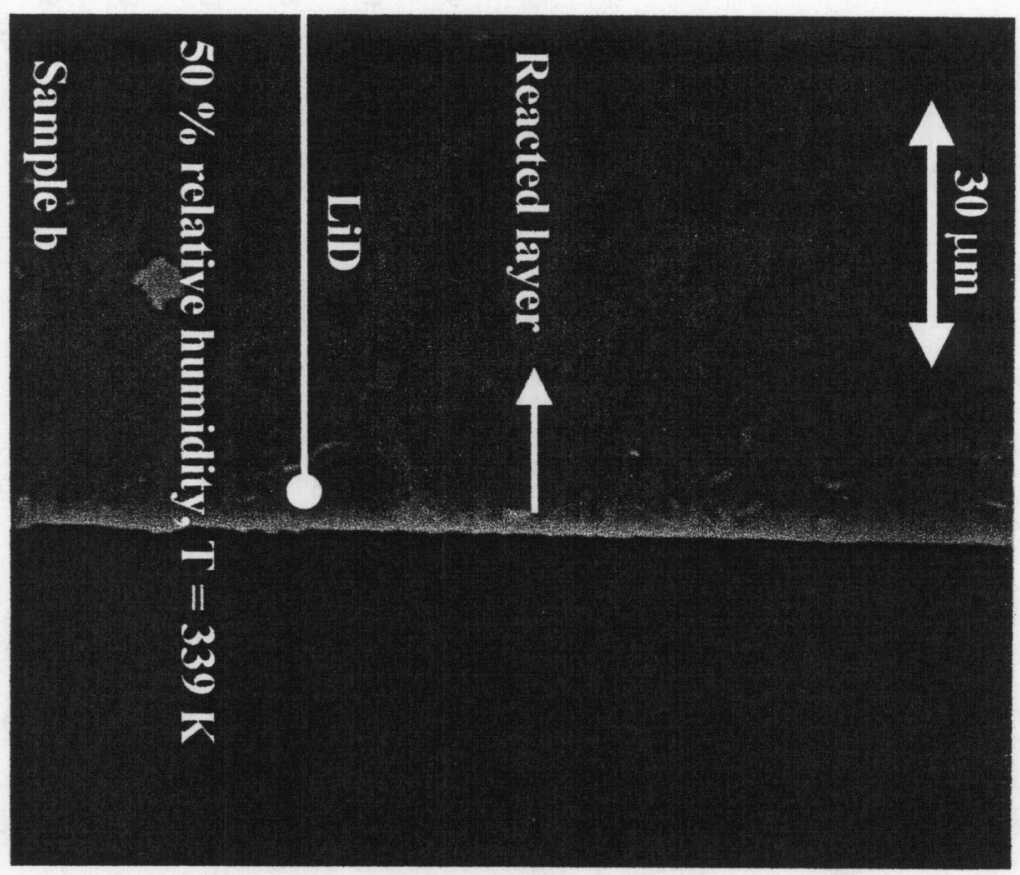




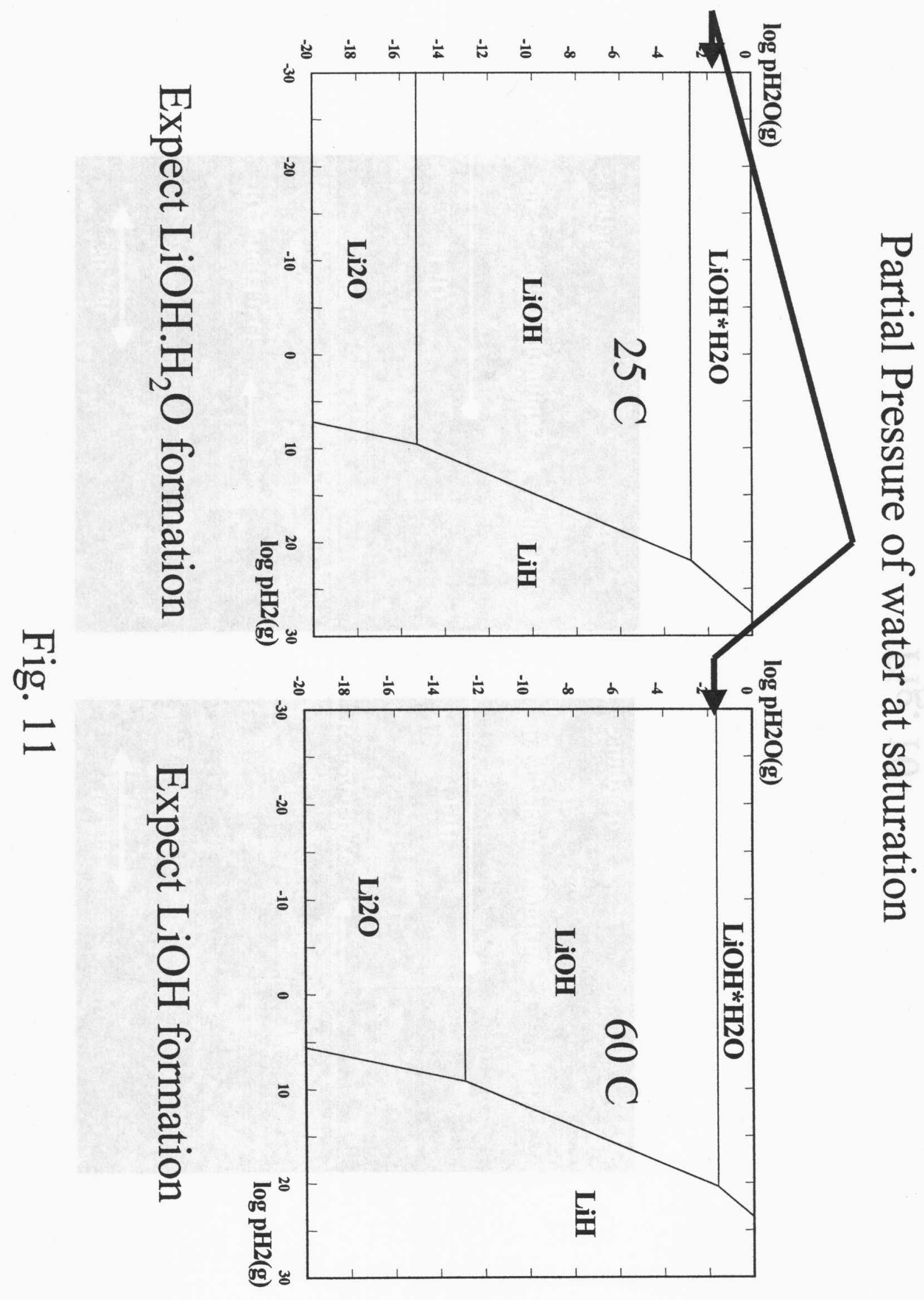




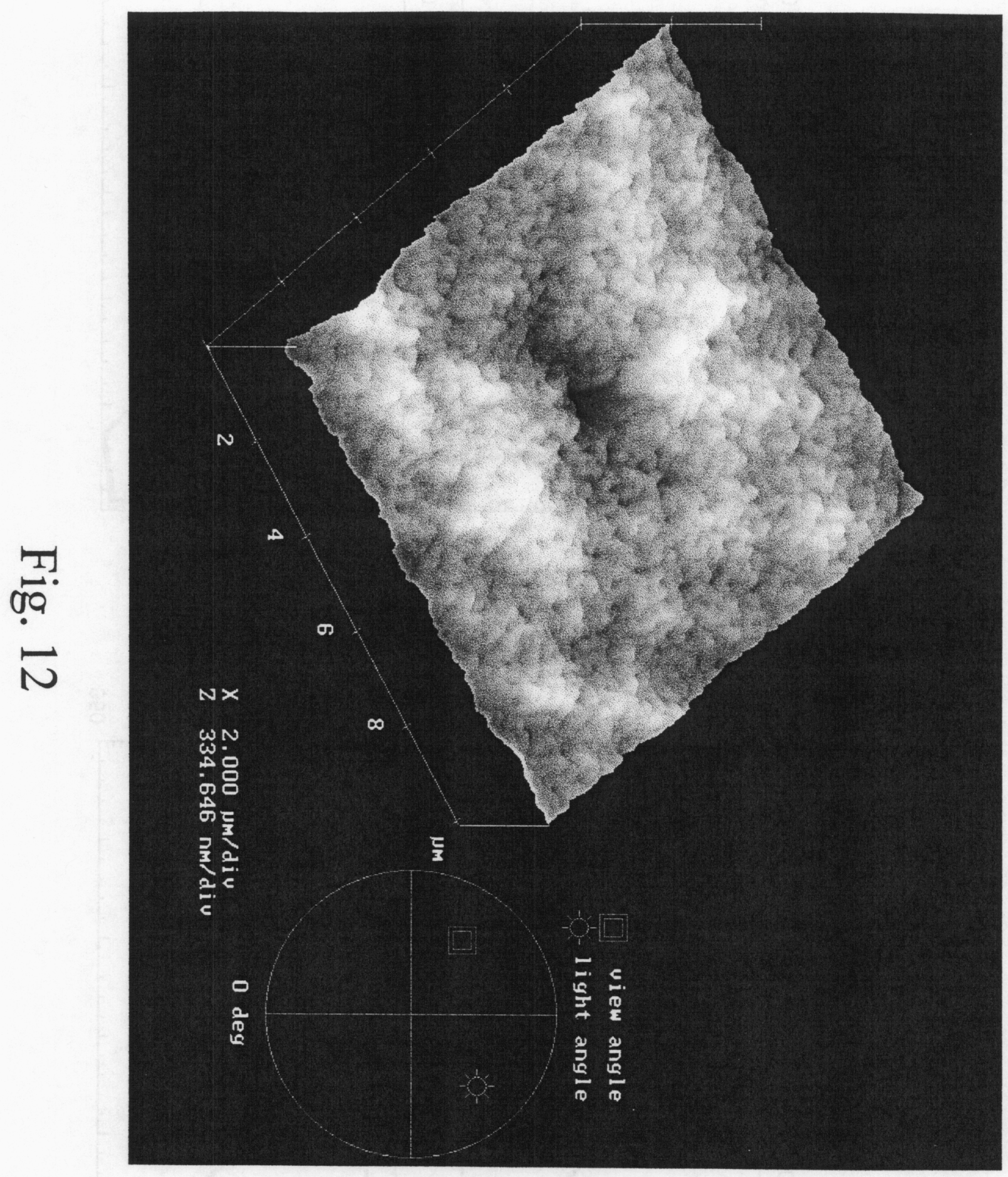




\section{Load Force $(\mu N)$}

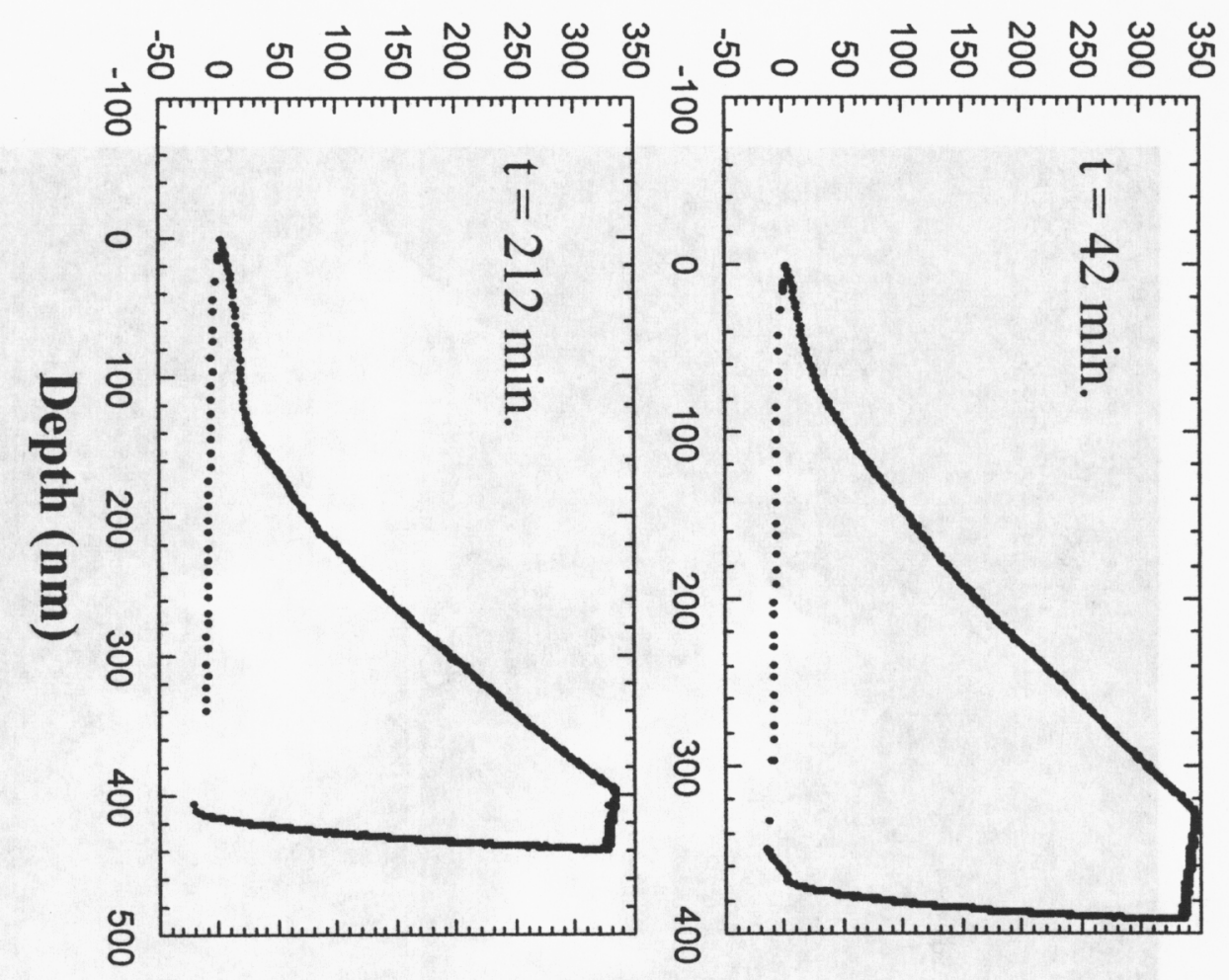

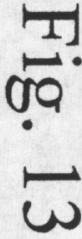

\section{Load Force $(\mu N)$}

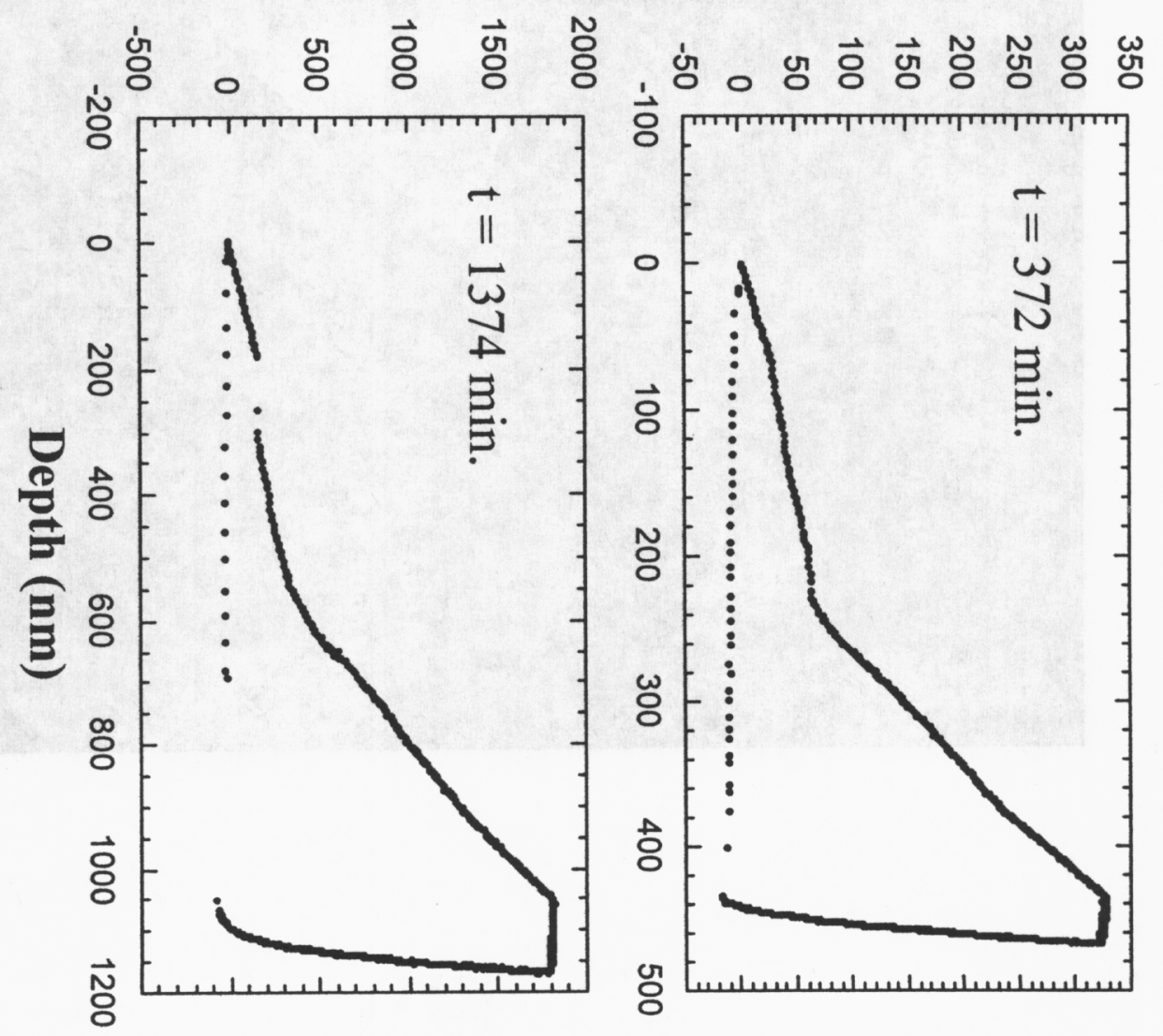




\section{Reaction layer thickness (nm)}

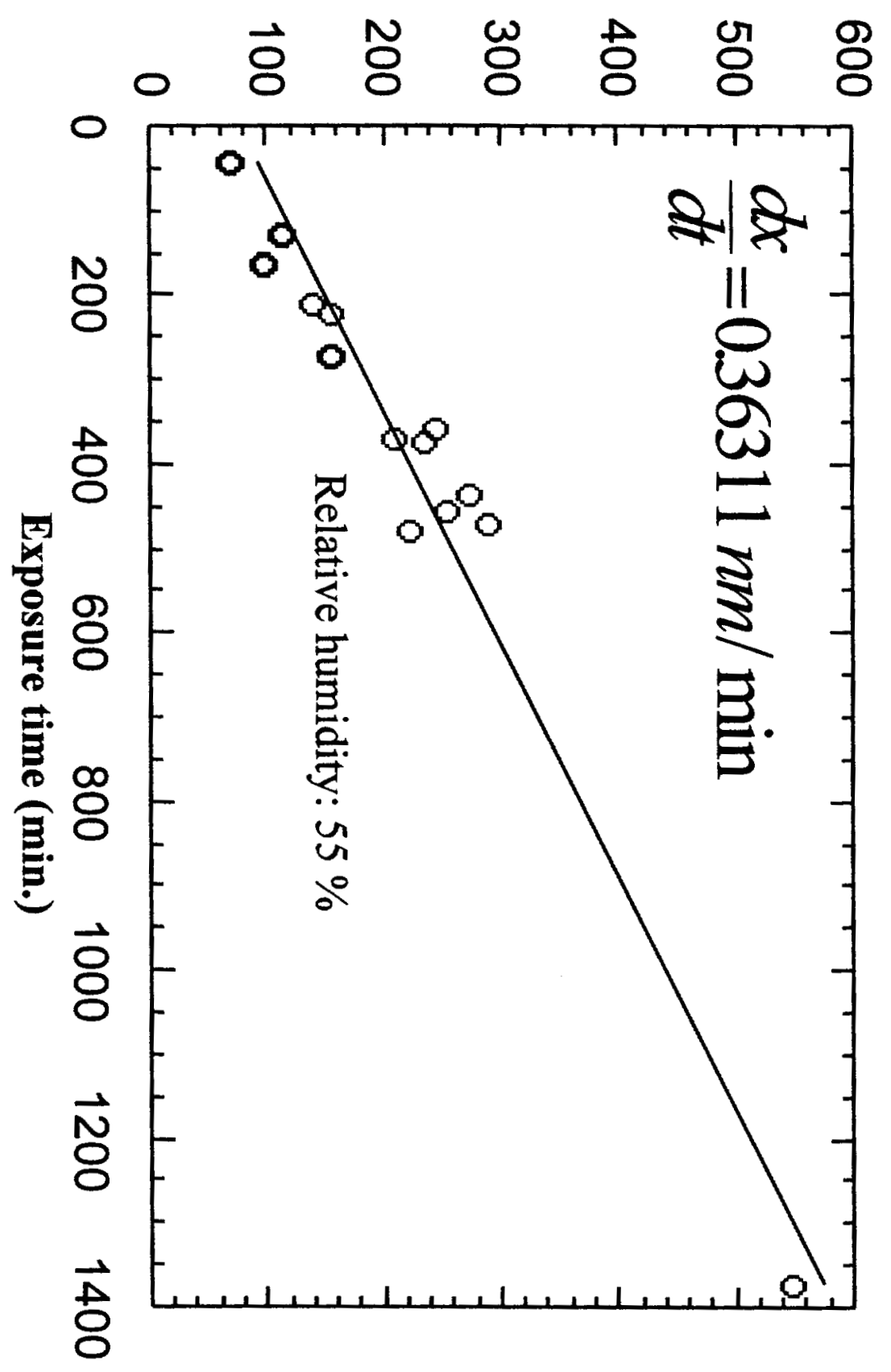




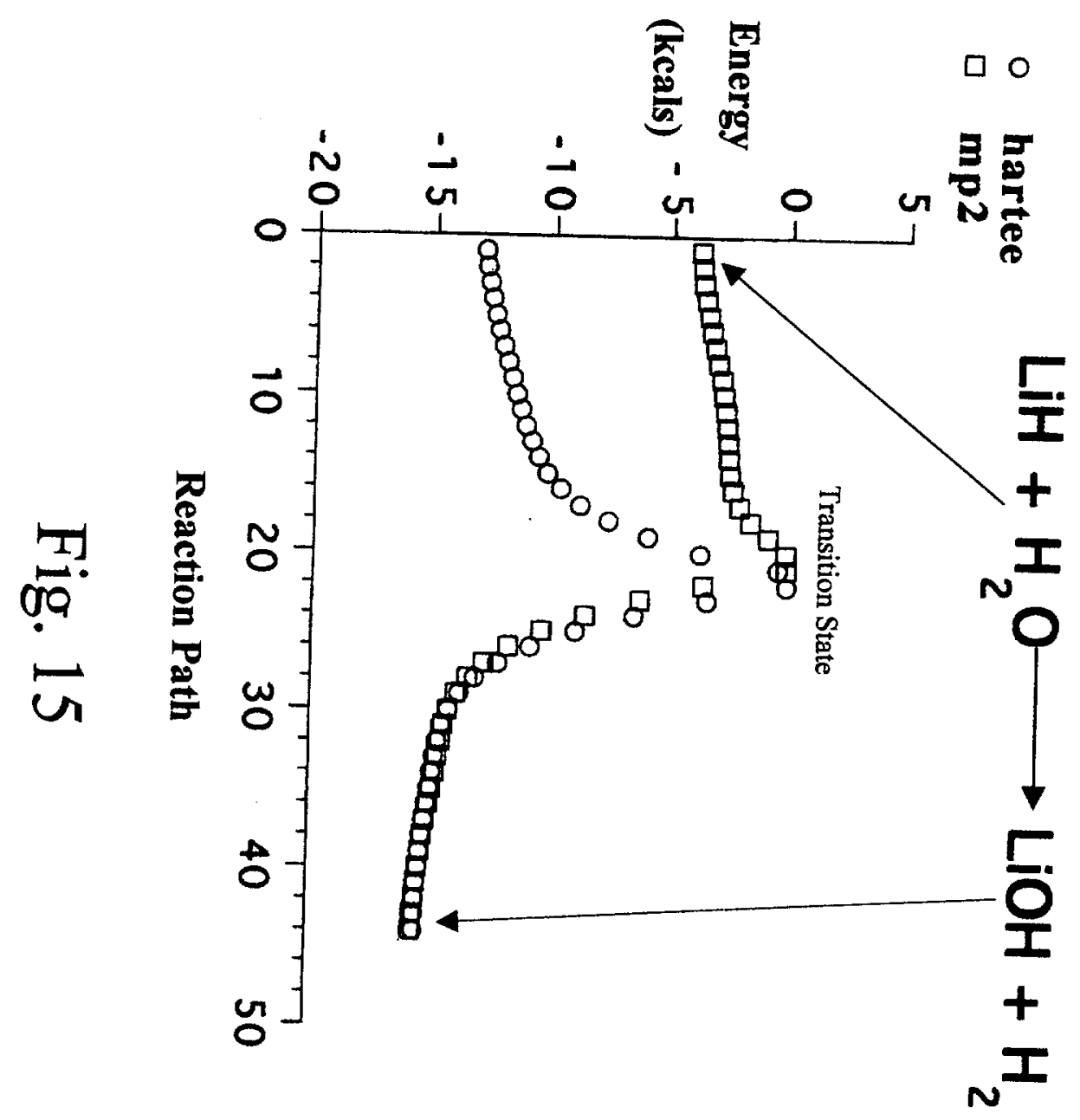

